\title{
A Clinicopathologic Study of Various Breast Lesions by Fine Needle Aspiration Cytology (FNAC)
}

\author{
Kazi Farzana Khanamª, Nasima Akter ${ }^{\mathrm{b}}$, Tarana Tabashum ${ }^{\mathrm{b}}$, Abu Khalid Muhammad Maruf Razac, g, \\ Asma Ul Hosna ${ }^{\mathrm{d}}$, Farzana Rahman ${ }^{\mathrm{e}}$, Afroza Begum ${ }^{\mathrm{f}}$
}

\begin{abstract}
Background: The expected and significant role of cytological diagnosis is to distinguish benign from malignant processes. Fine needle aspiration cytology (FNAC) of the breast has two main goals. One is to confirm a radiological and clinical benign lesion and avoid unnecessary surgery and the other is to confirm a malignant diagnosis and allow definite treatment planning.
\end{abstract}

Methods: In breast lesions, rapid diagnosis by aspiration cytology can be particularly useful for allaying the apprehension and anxiety of the patient whose apparent solid mass may turn to be a cyst, thus reducing the anguish and morbidity associated with unnecessary surgical procedures. If the lesions turn out to be malignant, the patient can be referred for immediate treatment on priority so that treatment is not unnecessarily delayed. Thus, aspiration cytology is used more and more in the diagnosis of benign and malignant lesions of the breast. It is a cost-effective and safe method that can differentiate benign and malignant lesions accurately. In advanced carcinoma or unwilling patients for surgery, it can form the basis of management. The objective of this study was to analyze cases of FNAC of breast lesions.

Results: This study was a cross-sectional study including all the patients with breast lump who attended Dhaka Community Medical college Hospital for FNAC. A total 50 cases of all ages and both sexes were included in this study. Smears made from aspirated material were collected and examined. Most of the aspirates were from females. There were more benign lesions (43 cases) as compared to malignant cases (seven cases). Fibroadenomas were the most benign

Manuscript submitted July 24, 2018, accepted September 5, 2018

aDepartment of Pathology, Dhaka Community Medical College, Dhaka, Bangladesh

${ }^{b}$ Department of Pathology, East West Medical College, Dhaka, Bangladesh

'Jahurul Islam Medical College, Bhagalpur, Bajitpur, Kishoregonj, Bangladesh

${ }^{\mathrm{d} D e p a r t m e n t}$ of Pathology, Prime Medical College, Rangpur, Bangladesh

eDepartment of Pathology, National Institute of Ophthalmology and Hospital, Dhaka, Bangladesh

fDepartment of Pathology, Anwer Khan Modern Medical College, Dhaka, Bangladesh

gCorresponding Author: A. K. M. Maruf Raza, Jahurul Islam Medical College, Bhagalpur, Bajitpur, Kishoregonj, Bangladesh.

Email: drmarufraza@gmail.com

doi: https://doi.org/10.14740/jcs366w lesion of breast. The age of malignant cases ranged from 21 to 60 years with a majority of cases in the age group of $41-50$ years (four cases, $57.1 \%)$.

Conclusion: FNAC is less time-consuming, safe, useful and highly accurate technique for breast masses and can segregate benign and malignant lesions with accuracy. Triple assessment by clinical, radiological and pathological examination is a standard approach in the evaluation of breast lumps. The clinical and radiological presentations of both benign and malignant lesions can be similar - as a hypoechoic focal mass, occasionally inflammatory lesions may mimic mass-like lesions or appears as non-homogenous regions on radiographs. Here, FNAC can play a major decisive diagnostic role and minimizing the requirement of biopsy.

Keywords: Fine needle aspiration cytology; Breast lump; Benign breast lump; Malignant

\section{Introduction}

Breast disease in women encompasses a spectrum of benign and malignant disorders. A palpable breast mass is the reason for consultation to a primary care physician in $42 \%$ of patients with breast symptoms, and accounts for more than half of breast complaints in women presenting to breast centers [1, 2]. Evaluation of breast lumps involves the rational use of a detailed history, clinical breast examination, imaging modalities and tissue diagnosis. Though the final diagnosis is made by histopathological examination of the excised tissue, routine excision of all breast lumps would not be rationale, because as much as $80 \%$ of lumps are benign [3]. Thus, the need is the utilization of less invasive and cost-effective methods of diagnosis without resorting to a more painful and invasive surgical biopsy. The modality should also be acceptable to the patient, accurate, easy to apply, reproducible and must not need too much preparations [4]. Considering patients' comfort, lack of requirement of anesthesia, rapid analysis and reporting, and few false positive results, fine needle aspiration cytology (FNAC) is an ideal initial diagnostic modality in breast lumps [5]. It is a popular technique used in the evaluation of breast masses due to its advantages of being sensitive, specific, simple, economical, safe, quick and acceptable to the patients [6]. Any breast lump needs a cytohistological diagnosis as even in 
Table 1. Distribution of Age With Breast Lesions

\begin{tabular}{llll}
\hline Age $($ years $)$ & Total number of cases and percentage $(\%)(\mathbf{n}=\mathbf{5 0})$ & Benign cases $(\mathbf{\%})(\mathbf{n}=\mathbf{4 3})$ & Malignant cases $(\mathbf{\%})(\mathbf{n}=\mathbf{0 7})$ \\
\hline $12-20$ & $18(36 \%)$ & $18(41.8 \%)$ & $0(0 \%)$ \\
$21-30$ & $15(30 \%)$ & $14(32.6 \%)$ & $1(14.3 \%)$ \\
$31-40$ & $5(10 \%)$ & $5(11.6 \%)$ & $0(0 \%)$ \\
$41-50$ & $8(16 \%)$ & $4(9.4 \%)$ & $4(57.1 \%)$ \\
$51-60$ & $4(8 \%)$ & $2(4.6 \%)$ & $2(28.6 \%)$ \\
Total & $50(100 \%)$ & $43(100 \%)$ & $07(100 \%)$ \\
\hline
\end{tabular}

expert hand the sensitivity of clinical diagnosis is 75\% [7]. For an accurate diagnosis of the breast lump, FNAC has gained wide popularity and acceptance as a quick, simple and reliable diagnostic procedure that can be carried as outpatient service. However, it has its own limitations in terms of sensitivity and specificity [8]. Most countries have now adopted this triple assessment approach (clinical, radiological and pathological) to breast diagnosis, with FNAC as the first-line pathological investigation in both screening and symptomatic populations, with the exception of cases where microcalcifications are present [9].

FNACs, especially in the hands of experienced cytopathologists, have high diagnostic accuracy, as high as $98.9 \%$ in some series $[10,11]$.

\section{Materials and Methods}

This hospital-based cross-sectional analytical study was carried out in Department of Pathology, Dhaka Community Medical College and Hospital for a total duration of 1 year 6 months from January 2017 to June 2018. Initial data were obtained by history taking and clinical examination along with radiological features. Cytology samples were obtained by FNAC performed on each patient respectively. FNAC was performed in the Department of Pathology by the pathologist under palpation guidance. The skin over the breast lump was cleaned with spirit cotton swab. The lesion was held with one hand and stabilized, while an average two to six passes were made by the other hand using a $10 \mathrm{~mL}$ airtight syringe with 23/25 gauze needle under constant negative pressure. Multidirectional sampling was done by moving the needle back and forth as per the recommendations of the American consensus meeting on breast needle procedures. Negative pressure was released be-

Table 2. Size of Breast Lump

\begin{tabular}{llll}
\hline \multirow{2}{*}{ Max dimension (cm) } & \multicolumn{3}{c}{ Number of breast lump } \\
\cline { 2 - 4 } & Benign & Malignant & Total \\
\hline$\leq 1 \mathrm{~cm}$ & $7(100 \%)$ & $0(0 \%)$ & 7 \\
$1.1-\leq 2 \mathrm{~cm}$ & $16(94.1 \%)$ & $1(5.89 \%)$ & 17 \\
$2.1-\leq 3 \mathrm{~cm}$ & $14(73.68 \%)$ & $5(26.32 \%)$ & 19 \\
$3.1-\leq 4 \mathrm{~cm}$ & $3(75 \%)$ & $1(25 \%)$ & 4 \\
$\geq 4.1 \mathrm{~cm}$ & $3(100 \%)$ & $0(0 \%)$ & 3 \\
\hline
\end{tabular}

fore removal of the needle. For each smear prepared by FNAC, papanicolaou staining was done on the alcohol-fixed smears.

Cytology findings were grouped into four categories: benign, non-diagnostic, suspicious or malignant. Of these, nondiagnostic and suspicious cases were excluded from this study. Specimen adequacy was defined by the cytopathologist, based on the Bethesda conference on breast cytology guidelines $[12,13]$. An adequate benign specimen required at least six well-visualized cell groups. A hypocellular or sparsely cellular specimen was considered unsatisfactory or non-diagnostic. A specimen was considered suspicious if the cellular findings were suggestive, but not diagnostic of malignancy. A malignant diagnosis was made when sufficient well-preserved malignant cells were identified. Information regarding the treating surgeon's clinical suspicion of the palpable mass and radiological findings was obtained from the medical record.

\section{Results}

FNAC was requested for a total of 50 breast lumps during the study period. There were only one male patient of gynecomastia and all other 49 were females. Age group of the patients ranged from 12 to 60 years. The demographic profile is shown in Table 1. Of these, $43(86 \%)$ were benign and 7 (14\%) were malignant (Table 1).

The age of all benign cases ranged from 12 to 60 years with a majority of cases between 12 and 20 years of age (18 cases, $36 \%$ ). The age of malignant cases ranged from 21 to 60 years with a majority of cases in the age group of 41 - 50 years (four cases, 57.1\%).

The malignant cases were mostly above the ages of 40 years. All the palpable breast lumps were in the range of $1-5$

Table 3. Side and Location of Breast Lump $(n=50)$

\begin{tabular}{llll}
\hline \multirow{2}{*}{ Quadrant } & \multicolumn{3}{c}{ Number of cases (\%) } \\
\cline { 2 - 4 } & Right & Left & Total \\
\hline Upper-outer & 13 & 11 & $24(48 \%)$ \\
Lower-outer & 2 & 0 & $2(4 \%)$ \\
Sub-areolar & 6 & 5 & $11(22 \%)$ \\
Upper-inner & 6 & 4 & $10(20 \%)$ \\
Lower-inner & 2 & 1 & $3(6 \%)$ \\
Total & $29(58 \%)$ & $21(42 \%)$ & $50(100 \%)$ \\
\hline
\end{tabular}


Table 4. Cytological Subclassification of Benign Breast Lump $(n=43)$

\begin{tabular}{lll}
\hline Cytological diagnosis & $\begin{array}{l}\text { No. of } \\
\text { cases }\end{array}$ & $\begin{array}{l}\text { Percentage } \\
(\%)\end{array}$ \\
\hline Fibroadenoma & 17 & $39.54 \%$ \\
\hline Fibrocystic change/other cystic lesion & 12 & $27.9 \%$ \\
\hline Inflammatory/mastitis/abscess & 8 & $18.6 \%$ \\
Lactational change/galactocele & 4 & $9.3 \%$ \\
Gynecomastia & 1 & $2.33 \%$ \\
Benign phyllodes & 1 & $2.33 \%$ \\
Total & 43 & $100 \%$ \\
\hline
\end{tabular}

$\mathrm{cm}$ and 19 breast lumps measured $2.1-3 \mathrm{~cm}$, of which five cases $(26.32 \%)$ were malignant. Seven breast lumps measured less than $1 \mathrm{~cm}$ and all were benign (Table 2).

Out of 50 cases, 29 cases $(58 \%)$ were in right breast and 21 cases $(42 \%)$ were in left breast. Among all the four quadrants, superolateral quadrant was the most common for breast lesions ( 24 cases, $48 \%$ ) as shown in Table 3. Forty-three $(86 \%)$ cases were benign (Table 4$)$ with the majority of cases (17 cases, 39.54\%) being fibroadenoma (Fig. 1), followed by fibrocystic change $(27.9 \%)$, inflammatory/ mastitis (18\%), galactocele or lactational changes $(9.3 \%)$, and only one case was benign phyllodes tumor $(2.33 \%)$. The cytological feature of fibrocystic change and malignant tumor (ductal carcinoma) is shown in Figures 2 - 4.

\section{Discussion}

FNAC is a useful tool in the preoperative evaluation of breast lumps [14]. Accurate preoperative evaluation is important as it allows for rapid referral of malignant cases for treatment and discharge of benign cases from the clinic and their return to routine follow-up [14]. FNAC can also be used in following up these benign cases except when otherwise indicated. FNAC is accurate, cheap and easy to perform, and is less invasive than core needle biopsies [15].

In this study, four cases were inadequate and were excluded. Therefore, 50 cases were studied. Obviously, the limitation of our study is that the sample size was small. But we still tried

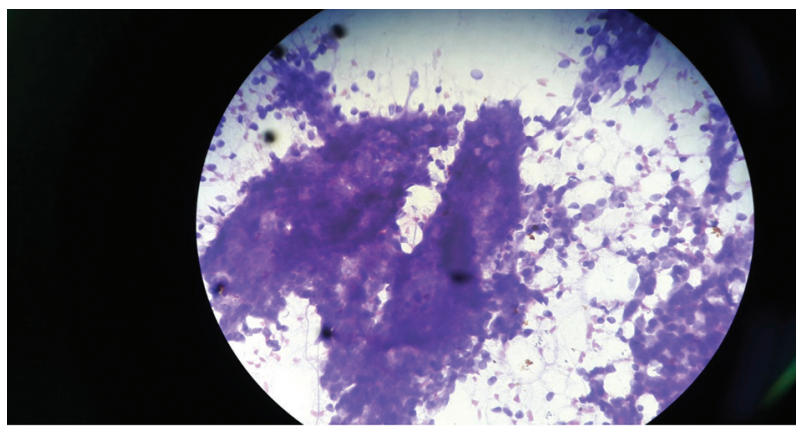

Figure 1. Cytology of fibroadenoma under microscope ( $\times 40$ objective).

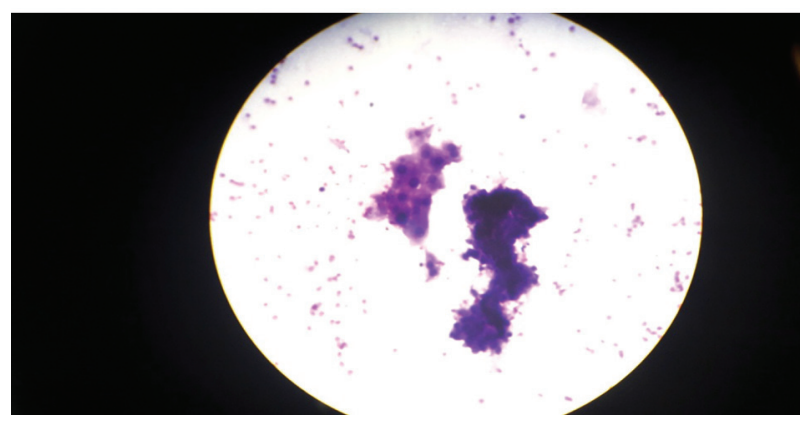

Figure 2. Fibrocystic change at $\times 10$ objective.

to observe the clinicopathological parameters of cases.

In this study of 50 cases, seven cases (14\%) were malignant and $43(86 \%)$ cases were benign. Yeoh et al [16] studied 1,533 breast masses on FNAC and found that $70.4 \%$ cases were benign and $4.4 \%$ cases were malignant. Similarly, Ganiat et al [17] studied 757 cases on FNAC and found that the majority of cases were benign $(50.2 \%)$, which was followed by malignant cases $(31.4 \%)$, suspicious malignant cases $(9.5 \%)$ and inflammatory cases (7.4\%). The percentage of benign cases in our study was closer to that of Yeoh et al [16].

In the present study, $43(86 \%)$ cases were benign with the majority of cases being fibroadenoma (17/43), followed by fibrocystic change (12/43), inflammatory/ mastitis (8/43), galactocele or lactational change (4/43), phyllodes tumor (1/43); seven $(6 \%)$ cases were malignant in the present study. Aslam et al [18] also documented fibroadenoma as the most common benign lesion $(71.3 \%)$ in their study. Unlike our study, Jayaram et al [19] in their study of 543 cases of FNAC found fibrocystic disease $(39.8 \%)$ as the most common lesion. Pattari et al [20] studied 71 histologically confirmed cases and documented infiltrating ductal carcinoma as the most common lesion (24/71).

The patients in our study were between 16 and 66 years of age with maximum incidence in the age group of $12-20$ years of $18(36 \%)$ cases, followed by 21 - 30 years of $15(30 \%)$ cases. The age of all benign cases ranged from 12 to 60 years with a majority of cases between 12 and 20 years of age (18 cases, 36\%). The age of malignant cases ranged from 21 to 60 years with a majority of cases in the age group of 41 - 50 years (four cases, 57.1\%).

Hussain [21] and Khemka et al [22] studied 50 patients and they found that the majority of patients were in the age group of 31 - 40 years. Khemka et al [22] observed that benign

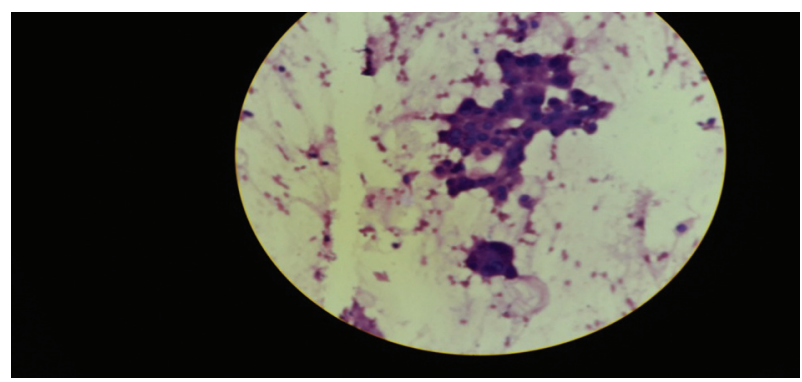

Figure 3. Apocrine metaplastic cells in fibrocystic change. 


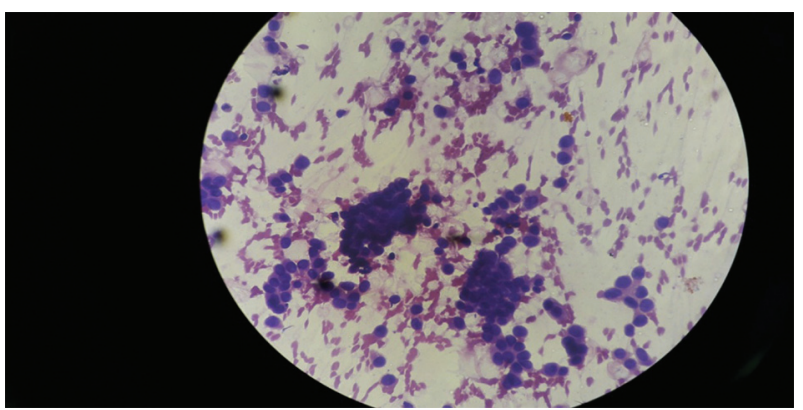

Figure 4. Ductal carcinoma under microscope at $\times 40$ objective.

lesions of breast were more commonly seen in younger age groups with the majority of patients found in the age group 30 - 34 years. Ganiat et al [17] reported the majority of patients with malignant lesions in the fourth to seventh decade of life. Among all the four quadrants, superolateral quadrant was the most common quadrant for breast lesions in the present study (24 cases, 48\%). Hussain [21] and Khemkha et al [22] also observed upper and outer quadrants as the commonest site. Out of 50 cases, $29(58 \%)$ cases were in the right breast and 21 $(42 \%)$ cases were in the left breast. Hussain [21] reported left breast involvement in $27(54 \%)$ cases and right breast involvement in $23(46 \%)$ cases.

In the present study, all the palpable breast lumps were in range of $1-5 \mathrm{~cm}$ and 19 breast lumps measured $2.1-3 \mathrm{~cm}$, of which five $(26.32 \%)$ cases were malignant. In lumps measuring more than $3 \mathrm{~cm}$, one (25\%) case was malignant out of four cases.

Ballo et al [23] studied 112 cases of the lumps with a size range of $1-12 \mathrm{~cm}$ and reported that $73.8 \%$ of the lumps with a larger size $(>2 \mathrm{~cm})$ and $28.38 \%$ with a size $<2 \mathrm{~cm}$ were malignant. Overall, breast lump with pain was the most common presenting complaint accounting up to $46.5 \%$.

\section{Conclusions}

From the above study, we conclude that triple assessment by clinical, radiological and pathological examination is a standard approach in the evaluation of breast lumps. Along with clinical history and examination, FNAC can help to take decision for surgery or conservative treatment. In advanced carcinoma or unwilling patients for surgery, it can form the basis of management. Therefore, FNAC should be used as a routine method for determining the nature of breast lump.

\section{Conflict of Interest}

None.

\section{References}

1. Salzman B, Fleegle S, Tully AS. Common breast problems. Am Fam Physician. 2012;86(4):343-349.
2. Bleicher RJ. Management of the palpable breast mass. In: Harris JR, Lippman ME, Morrow M, Osborne CK, editors. Diseases of the breast. Fifth. Philadelphia: Wolters Kluwer Health; 2014. pp. 29-37.

3. Pruthi S. Detection and evaluation of a palpable breast mass. Mayo Clin Proc. 2001;76(6):641-647; quiz 647648.

4. Tiwari M. Role of fine needle aspiration cytology in diagnosis of breast lumps. Kathmandu Univ Med J (KUMJ). 2007;5(2):215-217.

5. Khemka A, Chakrabarti N, Shah S, Patel V. Palpable breast lumps: fine-needle aspiration cytology versus histopathology: a correlation of diagnostic accuracy. The Internet Journal of Surgery. 2009;18.

6. Pradhan M, Dhakal HP. Study of breast lump of 2246 cases by fine needle aspiration. JNMA J Nepal Med Assoc. 2008;47(172):205-209.

7. Wilkinson S. Cytohistological diagnosis in breast lump. Acta Cytologica. 1989;33(5):613-619.

8. Dixon JM, Anderson TJ, Lamb J, Nixon SJ, Forrest AP. Fine needle aspiration cytology, in relationships to clinical examination and mammography in the diagnosis of a solid breast mass. Br J Surg. 1984;71(8):593-596.

9. Kocjan G, Bourgain C, Fassina A, Hagmar B, Herbert A, Kapila K, Kardum-Skelin I, et al. The role of breast FNAC in diagnosis and clinical management: a survey of current practice. Cytopathology. 2008;19(5):271-278.

10. Bukhari MH, Arshad M, Jamal S, Niazi S, Bashir S, Bakhshi IM, Shaharyar. Use of fine-needle aspiration in the evaluation of breast lumps. Patholog Res Int. 2011;2011:689521.

11. Panjvani SI, Parikh BJ, Parikh SB, Chaudhari BR, Patel KK, Gupta GS, Kodnani AH, et al. Utility of fine needle aspiration cytology in the evaluation of breast lesions. J Clin Diagn Res. 2013;7(12):2777-2779.

12. College of American Pathologists. Defining adequacy in nongynecologic cytology. 2003. Available: http://www. cap.org/apps//cap.portal [Accessed June 17, 2014].

13. The uniform approach to breast fine-needle aspiration biopsy. National Cancer Institute Fine-Needle Aspiration of Breast Workshop Subcommittees. Diagn Cytopathol. 1997;16(4):295-311.

14. Ellis IO, Humphreys S, Michell M, Pinder SE, Wells CA, Zakhour HD, Pathology UKNCCfBS, et al. Best Practice No 179. Guidelines for breast needle core biopsy handling and reporting in breast screening assessment. J Clin Pathol. 2004;57(9):897-902.

15. Garbar C, Cure H. Fine-needle aspiration cytology can play a role in neoadjuvant chemotherapy in operable breast cancer. ISRN Oncol. 2013;2013:935796.

16. Yeoh GP, Chan KW. Fine needle aspiration of breast masses: an analysis of 1533 cases in private practice. Hong Kong Med J. 1998;4(3):283-288.

17. Ganiat O, Omoniyi-Esan G, Osasan S, Titiloye N, Olasode B. Cytopathological review of breast lesions in Ile-Ife Nigeria. The Internet J. of Third World Med. 2008;8:1025.

18. Aslam HM, Saleem S, Shaikh HA, Shahid N, Mughal A, Umah R. Clinico- pathological profile of patients with 
breast diseases. Diagn Pathol. 2013;8:77.

19. Jayaram G, Alhady SF, Yip CH. Cytological analysis of breast lesions: a review of 780 cases. Malays J Pathol. 1996;18(2):81-87.

20. Pattari SK, Dey P, Gupta SK, Joshi K. Myoepithelial cells: any role in aspiration cytology smears of breast tumors? Cytojournal. 2008;5:9.

21. Hussain MT. Comparison of fine needle aspiration cytology with excision biopsy of breast lump. J Coll Physi- cians Surg Pak. 2005;15(4):211-214.

22. Khemkha A, Chakrabarti N, Shah S, Patel V. Palpable breast lumps: Fine needle aspiration cytology versus histopathology: A correlation of diagnostic accuracy. Internet J Surg. 2009;18:1.

23. Ballo MS, Sneige N. Can core needle biopsy replace fineneedle aspiration cytology in the diagnosis of palpable breast carcinoma. A comparative study of 124 women. Cancer. 1996;78(4):773-777. 